\title{
Outbreak
}

\section{Concomitant outbreaks of yellow fever and hepatitis E virus in Darfur States, Sudan, 2012}

\author{
Sarah S Ahmed ${ }^{1}$, Mohammed A Soghaier ${ }^{1}$, Sozan Mohammed ${ }^{2}$, Hayat S Khogali ${ }^{1}$, Muntasir M Osman ${ }^{1}$, \\ Abdalla M Abdalla ${ }^{1}$ \\ ${ }^{1}$ Directorate of Epidemiology and Zoonotic Diseases, Federal Ministry of Health, Khartoum, Sudan \\ ${ }^{2}$ National Public Health Laboratory, Federal Ministry of Health, Khartoum, Sudan
}

\begin{abstract}
Introduction: Yellow fever (YF) is a vector-borne disease transmitted to humans by infected Aedes mosquitoes, while hepatitis E virus (HEV) is a waterborne disease that is transmitted through the fecal-oral route. Both diseases have very close clinical presentation, namely fever, jaundice, malaise, and dark urine; they differ in severity and outcome.

Methodology: In this cross-sectional, laboratory-based study, an attempt was made to measure the correlation of concomitant YF and HEV infection in Darfur States during the previous YF outbreak in 2012.

Results: Results found concomitant outbreaks of YF and HEV at the same time with very weak statistical correlation between the two infections during the outbreak period, with Cramer's V correlation 0.05 and insignificant $\mathrm{p}$ value of 0.86 .

Conclusions: This correlation indicates that clinicians and care providers in tropical areas have to deal with clinical case definitions used for disease surveillance very carefully since prevalence of HEV infection is relatively common and this increases the possibility of misclassification and missing YF cases, particularly initial index cases, in a season or outbreak.
\end{abstract}

Key words: yellow fever; hepatitis E virus; co-infection; Darfur.

J Infect Dev Ctries 2016; 10(1):024-029. doi:10.3855/jidc.6342

(Received 29 November 2014 - Accepted 07 April 2015)

Copyright (C 2016 Ahmed et al. This is an open-access article distributed under the Creative Commons Attribution License, which permits unrestricted use, distribution, and reproduction in any medium, provided the original work is properly cited.

\section{Introduction}

Yellow fever (YF) virus is one of zoonotic Flavivirus that is endemic in the tropics of Africa and South America [1]. Its clinical presentation varies from mild flu-like illness to hemorrhagic fever and may lead to death, with a case fatality rate ranging between $20 \%$ and $50 \%$ [2]. The disease is transmitted by Aedes mosquito species and maintained in enzootic cycles, infecting non-human primates (e.g., monkeys). Humans usually acquire the infection accidently when they are visiting or working in the jungle $[1,3]$. On the other hand, its urban cycle occurs with the presence of relatively large population living in close proximity to mosquito species (Aedes aegypti) capable of virus transmission and outbreak propagation $[1,3]$.

YF is known to have occurred in West, East, and Central Africa, including Sudan, since the 1940s when an outbreak was reported from the Sudan-Ethiopia border. Subsequently, YF spread along the Omo River valley, causing a major epidemic between 1960 and 1962 [2]. In 1989, a serological survey in Merwie and Karima towns in North Sudan that involved patients with acute febrile illness documented the presence of disease-specific antibodies with possible immunological cross-reaction with Sandfly fever Napels virus [4]. In 2003 and 2005, other outbreaks took place in Imatong, southern Sudan, and South Kordofan State of Sudan, with considerable morbidities and mortalities [5,6]. More recently in 2012 and 2013, a major outbreak occurred in the Darfur region in the western part of Sudan, a region that had never been covered by YF vaccination before [7].

Hepatitis E virus (HEV) is a waterborne disease that transmitted through the oral-fecal route, generally presents with mild to moderate clinical severity, and even passes unnoticed in the majority of cases. HEV infection is only considered as a serious health event when it selectively affects pregnant women; then, disastrous outcomes for both mother and fetus are usually anticipated in terms of miscarriage, prematurity, and maternal mortality [8,9]. HEV outbreaks have occurred in Sudan during the last couple of years in different areas of the country [10]. 
During last YF outbreak in Darfur states, simultaneous co-existence of both YF and HEV infections was observed in affected localities. This coexistence had further complicated the outbreak interpretation since the clinical manifestations of the two infections are almost identical. It was impossible to distinguish between the two infections without specific laboratory serological tests. One of the most important tools for communicable disease outbreak investigation and containment is the establishment of standard operational cases definition for case finding, reporting, and treatment [11]. Co-existence of such infections with shared cardinal clinical features is believed to affect both sensitivity and predictive power of a case definition, with a direct effect on hindering outbreak control dynamics. The nationally recommended operational case definition of YF during that outbreak was any case of fever, vomiting with or without jaundice, or bleeding tendency in the absence of positive blood film for malaria or any other obvious cause of fever [12]. According to that case definition, the total suspected cases that had been reported to the national disease surveillance system was 844, with 171 deaths, resulting in a case fatality rate (CFR) of more than 20\%. During that outbreak, large-scale containment interventions were carried out, including mass vaccination campaigns that covered more than two million people, vector surveillance/control, and case management activities. Laboratory capacity was strengthened during the outbreak; all required materials and equipment were made available. Technical laboratory support was provided by different partners, namely the Institute Pasteur in Dakar (PID) and the Naval American Medical Research Unit 3 (NAMRU-3). That support and strengthening of laboratory capacity enabled the national public health laboratory and national surveillance system to thoroughly investigate as many as possible of the reported suspected YF cases during the outbreak period. Interesting findings were obtained from the analysis of outbreak samples that confirmed concomitant dual outbreaks of YF and HEV in the same population. This study reports the co-existence of YF and HEV infections in Darfur region during the last YF outbreak season and highlights the potentiality of clinical misclassifications when referring to a clinical standard case definition.

\section{Methodology}

Study design

This cross-sectional study included demographic, clinical, and laboratory data obtained from the national communicable disease surveillance database for the recent YF outbreak that took place from September to December 2012 in Darfur states.

\section{Study area}

Darfur region is located in the western part of Sudan and composed of five administrative states (provinces); it borders Northern State, North/South Kordofan States, and has international borders with neighboring countries Libya, Chad, the Central African Republic, and the new Republic of South Sudan [13]. Darfur region covers almost $20 \%$ of Sudan's land space. Since 2003, the region has witnessed several events of turmoil such as conflicts, political complications, and humanitarian crises [14]. This passively influenced the socio-demographic dynamics in the region, resulting in the current agony of population displacement, fragile health system, security instability, and inaccessibility to the civil service.

\section{Study population}

All reported suspected YF cases throughout outbreak period were included in this analysis, particularly those who had been tested for both YF and HEV. Cases with missing data or incomplete clinical records were excluded.

\section{Data collection tools}

Data were collected through the standard Sudanese national surveillance system reporting format, including the standard YF case investigation form and outbreak line list.

\section{Laboratory analysis}

The total number of samples that were tested for YF and other viruses was 134, while 80 samples were tested for both YF and HEV. Enzyme-linked immunosorbent assay (ELISA) technique was performed to confirm the presence of both YF and HEV by detecting IgM antibodies, which is usually an indicator for recent infection $[15,16]$. The reagent kits used were obtained from MP Diagnostics from Geneva, Switzerland and the Centers for Disease Control and Prevention IgM capture assay for HEV and YF, respectively $[17,18]$.

\section{Results}

A total of 80 cases were investigated and analyzed; males represented $84 \%$ of the study population. The mean age of participants was 25 years (standard deviation of 11 years). A total of $38.8 \%$ of the cases 
resided in urban settlements: $32.5 \%$ were from North Darfur State, 22.5\% from Central Darfur State, 20\% from South Darfur State, and the rest from different areas of Darfur region. More than $48 \%$ of the cases had temporal jobs (mainly daily wage laborers), while $20 \%$ were mine workers (mainly traditional gold mining in Darfur region), and 12\% were shepherds. Medical review history showed that $97.5 \%$ of cases had fever during the current illness, $62.5 \%$ were found to have hemorrhagic manifestations, and more than $58.8 \%$ had developed clinical manifestations of jaundice. Main characteristics of the study participants are presented in Table 1.

With respect to serological virology, 37 (64\%) of cases were positive for YF, and $10(27 \%)$ of them died as a result of the disease; details of YF patients are summarized in Table 2 . Thirty patients $(38 \%)$ were found to be positive for HEV, of which more than $60 \%$ were males and in the younger age group. Mine workers and farmers were the most affected by HEV, and there were no mortalities reported among those people who had only HEV. Thirteen (16.3\%) participants were concomitantly positive to both YF IgM and HEV IgM. Cramer's V statistical correlation value was found to be 0.05 and with a $p$ value of 0.86 , which indicates very weak statistical correlation between YF and HEV; interestingly, the mortality in patients who had both YF and HEV group was lower than the mortality among patients with YF only $(7.7 \%$ and $37 \%$, respectively). Details of patients with concomitant YF and HEV infections and statistical correlation are summarized in Tables 3 and 4.

\section{Discussion}

This is the first study that attempts to measure the correlation between YF and HEV infection among outbreaks in Darfur region. The study reveals that the most affected age group was the 14-39 year group because people in this group move more, usually looking for work; in this context, traditional gold mining is a considerable factor. This was also observed in Kenya in 1992-1993, where researchers reported that more than $70 \%$ of cases between 10-39 years of age were found to have higher YF prevalence

Table 1. Distribution of basic characteristics of study population.

\begin{tabular}{|c|c|c|c|}
\hline Characteristic & & Count (n) & Percent (\%) \\
\hline Outcome & Lived & 60 & 75 \\
\hline Gender & Male & 67 & 84 \\
\hline \multirow[t]{4}{*}{ Age group (years) } & $<14.9$ & 13 & 16 \\
\hline & $15-29.9$ & 49 & 61 \\
\hline & $30-44.9$ & 11 & 14 \\
\hline & Mean age (years) & 25 & $\mathrm{SD}=12$ \\
\hline \multirow[t]{6}{*}{ Occupation } & Butcher & 1 & 1 \\
\hline & Driver & 1 & 1 \\
\hline & Farmer & 9 & 11 \\
\hline & Housewife & 1 & 1 \\
\hline & Mine worker & 16 & 20 \\
\hline & Student & 5 & 9 \\
\hline \multirow[t]{5}{*}{ State } & Central Darfur & 18 & 23 \\
\hline & East Darfur & 2 & 3 \\
\hline & North Darfur & 31 & 39 \\
\hline & South Darfur & 16 & 20 \\
\hline & West Darfur & 13 & 17 \\
\hline \multirow[t]{3}{*}{ Complaint } & Fever & 78 & 98 \\
\hline & Jaundice & 47 & 59 \\
\hline & Bleeding tendency & 50 & 63 \\
\hline \multirow[t]{2}{*}{ Diagnosis } & Yellow fever & 37 & 64 \\
\hline & Hepatitis E & 30 & 38 \\
\hline
\end{tabular}


[19]. Males had higher YF positive serological outcome compared to females in this study, which suggests high exposure to infected jungle mosquitoes (> 70\% had unfixed jobs or were mine workers). Knowing that YF is transmitted to humans through the Aedes mosquito while HEV infection is one of the waterborne diseases that has been known to be circulating in Darfur region since 2004 [10], it is not surprising in this analysis to find that $16 \%$ of the study population had both YF and HEV infections at the time of outbreak. The statistical correlation between YF and HEV was demonstrated in this study by applying Cramer's V correlation statistic, which is used to quantify the correlation between two nominal variables. Cramer's V value was 0.05 , which shows a very weak relationship between having concomitant infection with both YF and HEV, and it is generally not statistically acceptable according to the cutoff

Table 2. Characteristics of patients with yellow fever.

\begin{tabular}{lccc}
\hline Characteristic & & Count (n) & Percent (\%) \\
\hline Outcome & Lived & 27 & 73 \\
& Died & 10 & 27 \\
Gender & Male & 31 & 84 \\
Age group (years) & Female & 6 & 16 \\
& $<14.9$ & 6 & 16 \\
& $15-29.9$ & 22 & 60 \\
Occupation & $30-44.9$ & 2 & 5 \\
& $>45$ & 1 & 3 \\
& Butcher & 4 & 11 \\
& Farmer & 6 & 16 \\
& Mine worker & 5 & 5 \\
\end{tabular}

Table 3. Yellow fever and hepatitis E virus cross-tabulation and correlation.

\begin{tabular}{cccc}
\hline Cross-tabulation & YF positive & YF negative & Total \\
\hline HEV positive & 13 & 17 & 30 \\
HEV negative & 24 & 26 & 50 \\
Cramer's V value & $0.05^{*}$ & & \\
P value & 0.86 & & \\
*Cutoffs: $<0.15:$ very weak correlation; $0.16-0.3:$ weak to moderate correlation; $0.3-0.5:$ strong to very strong correlation; $0.5-.9:$ redundant and perfect \\
correlation
\end{tabular}

Table 4. Characteristics of participants who had concomitant yellow fever and hepatitis $\mathrm{E}$ virus.

\begin{tabular}{lccc}
\hline Characteristic & & Count (n) & Percent (\%) \\
\hline Outcome & Lived & 12 & 92 \\
Gender & Died & 1 & 8 \\
& Male & 12 & 92 \\
Age group (years) & Female & 1 & 8 \\
& $15-29.9$ & 8 & 62 \\
& $30-44.9$ & 4 & 31 \\
Occupation & $>45$ & 1 & 8 \\
& Butcher & 1 & 8 \\
& Farmer & 2 & 46 \\
& Mine worker & 6 & 8 \\
Complaint & Shepherd & 1 & 8 \\
& Student & 1 & 15 \\
& No fixed job & 2 & 92 \\
\end{tabular}


values [20] (Table 3). This supports the hypothesis and the current state of knowledge regarding both YF and HEV. No biological plausibility is currently known that links these two types of viruses, though they were clinically and concomitantly found in this outbreak, which suggests that there was an ongoing outbreak of HEV along with the YF during that particular time. The co-existence of YF and HEV infection outbreaks in Darfur might be explained by the fact that the YF outbreak occurred immediately after the rainy season. Usually in many parts of Sudan, including Darfur States, nomadic people and animal keepers store water in large ground ponds (hafeers), and they use this water for drinking, cooking, and other domestic purposes, which might be the source of contamination and HEV infection [10]. In addition, when someone takes water from hafeer, some water leaks behind and it fills the footprints of their animals (small, deep, and dark holes), which offers a very suitable environment for mosquito breeding, particularly Aedes mosquito, the responsible vector for YF and some other hemorrhagic fevers; this finding was observed in several entomological surveys $[21,22]$. Moreover, the circulation of both YF and HEV in Sudan and some neighboring countries is well known, particularly in Ethiopia [23]. Based on this summary, it is reasonable to assume that the HEV outbreak started before YF and that the majority of HEV cases went unnoticed by the surveillance system since the disease is of mild severity, particularly among the young people who were affected by YF initially [7]. In addition, increasing sensitivity of the surveillance system during the outbreak led to HEV cases being reported to the health facilities as well. The same phenomenon was reported from Port Sudan, the capital city of the Red Sea State, during 2010, which had been affected by a dual outbreak of HEV and dengue fever according to the disease surveillance system, Sudan Federal Ministry of Health [24,25]. Both dengue and YF are from the same virological family and are transmitted by the same means [1]. Moreover, during the South Kordofan YF outbreak in 2005, investigators confirmed the co-existence of chikungunya; both YF and chikungunya are transmitted to humans by the same mosquito [6]. On the other hand, concurrent infection of mosquito-borne disease with another waterborne disease, such as dengue fever and hepatitis A infection or malaria with typhoid fever, is quite often reported from different developing countries [26]. Also, co-infections due to Leptospira and HEV were reported from some tropical countries, but this is the first time the co-existence of YF with HEV as outbreaks in our African region was reported [27].

\section{Conclusions}

This study has reported the concomitant outbreaks of YF and HEV infection in Darfur States during 2012. This demonstrates how important it is that clinicians, epidemiologists, and other healthcare providers carefully set the operational case definitions and management planning, particularly during heath emergencies and disease outbreaks. Further studies should be carried out to explore the severity of concomitant infections and their relationship with clinical outcomes.

\section{Acknowledgements}

The authors thank the epidemiology directorate teams in Sudan at state and federal levels for providing logistic, technical, and conceptual support during the period of this outbreak. The authors also thank the health cluster partners, particularly WHO and UNICEF, Sudan offices for the support provided. Finally, the authors thank the National Public Health Laboratory team, NAMRU-3, and PID for strengthening the diagnostic technical capacities that enabled the surveillance system to perform better.

\section{References}

1. Stanley Falkow P, P. James J. Champoux, Kenneth J. Ryan M, C. George Ray M (2004) in Sherris Medical Microbiology Introduction to Infectious Diseases. $9 \mathrm{p}$.

2. Gubler DJ (2004) The changing epidemiology of yellow fever and dengue, 1900 to 2003: full circle? Comp Immunol Microbiol Infect Dis 27: 319-330.

3. CDC (2011) Transmission of Yellow Fever Virus. 24/7: 1.

4. Watts DM, El-Tigani A, Botros BA, Salib AW, Olson JG (1994) Arthropod-Borne Viral Infectious Associated with a Fever Outbreak in the Northern Province of Sudan. J Trop Med Hyg 97: 2.

5. Onyango CO, Ofula VO, Sang RC, Konongoi SL, Sow A, De Cock KM, Tukei PM, Okoth FA, Swanepoel R, Burt FJ, Waters NC, Coldren RL (2004) Yellow fever outbreak, Imatong, southern Sudan. Emerg Infect Dis 10: 1064.

6. Gould LH, Osman MS, Farnon EC, Griffith KS, Godsey MS, Karch S, Mulenda B, El Kholy A, Grandesso F, de Radiguès X, Brair ME, Briand S, El Tayeb el SM, Hayes EB, Zeller H, Perea W (2008) An outbreak of yellow fever with concurrent chikungunya virus transmission in South Kordofan, Sudan, 2005. Trans R Soc Trop Med Hyg 102: 1247-1254.

7. Soghaier MA, Hagar A, Abbas MA, Elmangory MM, Eltahir KM, Sall AA (2013) Yellow Fever outbreak in Darfur, Sudan in October 2012; the initial outbreak investigation report. J Infect Public Health 6: 370-376.

8. Boccia D, Guthmann JP, Klovstad H, Hamid N, Tatay M, Ciglenecki I, Nizou JY, Nicand E, Guerin PJ (2006) High mortality associated with an outbreak of hepatitis E among 
displaced persons in Darfur, Sudan. Clin Infect Dis 42: 16791684.

9. Kumar A, Beniwal M, Kar P, Sharma J, Murthy N (2004) Hepatitis E in pregnancy. Int J Gynecol Obstet 85: 240-244.

10. Guthmann J-P, Klovstad H, Boccia D, Hamid N, Pinoges L, Nizou JY, Tatay M, Diaz F, Moren A, Grais RF, Ciglenecki I, Nicand E, Guerin PJ (2006) A large outbreak of hepatitis E among a displaced population in Darfur, Sudan, 2004: the role of water treatment methods. Clin Infect Dis 42: 1685-1691.

11. Sacks JJ (1985) Utilization of case definitions and laboratory reporting in the surveillance of notifiable communicable diseases in the United States. Am J Public Health 75: 14201422 .

12. Elhassan M, Malik M, Mahgoub A, Khogali H, Elmagboul B, Elfadil T, Okoued S, Eltahir K (2014) Combating yellow fever outbreak in Darfur States, Sudan, 2012. Int J Infect Dis 21: 217.

13. Ariel L. PJMS (2006) Sudan's Geography. http://www.globaldreamers.org/holocaust/darfur/geography.

14. Straus S (2005) Darfur and the genocide debate. Foreign Aff: 123-133.

15. Monath TP, Nystrom RR (1984) Detection of yellow fever virus in serum by enzyme immunoassay. Am J Trop Med Hyg 33: $151-157$

16. Goldsmith R, Yarbough P, Reyes GR, Fry K, Gabor K, Kamel M, Zakaria S, Amer S, Gaffar Y (1992) Enzymelinked immunosorbent assay for diagnosis of acute sporadic hepatitis E in Egyptian children. Lancet 339: 328-331.

17. Pas SD, Streefkerk RH, Pronk M, Robert A, Beersma MF, Osterhaus AD, van der Eijk AA (2013) Diagnostic performance of selected commercial HEV IgM and IgG ELISAs for immunocompromised and immunocompetent patients. J Clin Virol 58: 629-634.

18. World Health Organization (2004) Manual for the monitoring of yellow fever virus infection; Protocol for performing the CDC IgM capture assay. Geneva 27, Switzerland: http://www.who.int/vaccines-documents/. 62(44-53) p.

19. Sanders EJ, Marfin AA, Tukei PM, Kuria G, Ademba G, Agata NN, Ouma JO, Cropp CB, Karabatsos N, Reiter P, Moore PS, Gubler DJ (1998) First recorded outbreak of yellow fever in Kenya, 1992-1993. I. Epidemiologic investigations. Am J Trop Med Hyg 59: 644-649.

20. Powers DA, Xie Y (2008) Statistical methods for categorical data analysis. Emerald Group Publishing.

21. Carter HR (1924) Preferential and Compulsory Breeding Places of Aedes (Siegomyia) aegypti and their Limits. Published by United Fruit Company, Boston, Mass. 228-238.

22. Marquetti FMC, Fuster CC, Estévez TG, Somarriba LL (2010) [Contributions made by the Cuban advisory work to the entomological surveillance in Haiti]. Rev Cubana Med Trop 63: 177-180. [Article in Spanish].

23. Aseffa A (1993) Viral diseases in Ethiopia: a review. East Afr Med J 70: 624-626.

24. Rayis DA, Jumaa AM, Gasim GI, Karsany MS, Adam I (2013) An outbreak of hepatitis E and high maternal mortality at Port Sudan, Eastern Sudan. Pathog Glob Health 107: 66-68.

25. Seidahmed OM, Siam HA, Soghaier MA, Abubakr M, Osman HA, Abd Elrhman LS, Elmagbol B, Velayudhan R (2012) Dengue vector control and surveillance during a major outbreak in a coastal Red Sea area in Sudan. East Mediterr Health J 18: 1217-1224.

26. Syed Ahmed Zaki VL (2011) Concurrent infection of dengue fever and hepatitis A infection: A case report. Indian J Crit Care Med 15: 3.

27. Behera B1, Chaudhry R, Pandey A, Mohan A, Dar L, Premlatha MM, Gupta E, Broor S, Aggarwal P (2010) Coinfections due to leptospira, dengue and hepatitis $\mathrm{E}$ : a diagnostic challenge. $\mathrm{J}$ Infect Dev Ctries 4: 3. doi: $10.3855 /$ jidc. 535 .

\section{Corresponding author}

Dr. Mohammed A. Soghaier

Directorate of Epidemiology and Zoonotic Diseases

Federal Ministry of Health

Khartoum, Sudan

Phone: +249912387175

Email: soghaier@gmail.com

Conflict of interests: No conflict of interests is declared. 